\title{
Prognostic value of MICA/B in cancers: a systematic review and meta-analysis
}

\author{
Yijing Zhao ${ }^{1}$, Naifei Chen ${ }^{1}$, Yu Yu ${ }^{1}$, Lili Zhou ${ }^{1}$, Chao Niu ${ }^{1}$, Yudi Liu $^{1}$, Huimin Tian ${ }^{1}$, \\ Zheng Lv' ${ }^{1}$, Fujun Han $^{1}$ and Jiuwei Cui ${ }^{1}$ \\ ${ }^{1}$ Cancer Center, The First Hospital of Jilin University, Changchun, 130021, China
}

Correspondence to: Jiuwei Cui, email: cuijw@jlu.edu.cn

Keywords: $M I C A, M I C B$, prognosis, cancer, meta-analysis

Received: August 02, $2017 \quad$ Accepted: September 22, $2017 \quad$ Published: October 03, 2017

Copyright: Zhao et al. This is an open-access article distributed under the terms of the Creative Commons Attribution License 3.0 (CC BY

3.0), which permits unrestricted use, distribution, and reproduction in any medium, provided the original author and source are credited.

\section{ABSTRACT}

Purpose: MHC class I chain related-proteins A (MICA) and B (MICB) are natural killer group 2D ligands that mediate tumor surveillance. Several studies have suggested that MICA/B levels predict clinical outcomes in patients with cancer; however, this remains contentious. Here, we present a systematic review and metaanalysis of available studies of the prognostic value of MICA/B in cancer.

Materials and Methods: We searched PubMed, Embase, Clinicaltrials.gov, and Cochrane Library to identify studies published from inception to July 2017 that assessed MICA/B in patients with cancer. The hazard ratio (HR) and $95 \%$ confidence interval (CI) of MICA/B were extracted for overall survival (OS) analysis.

Results: A total of 19 studies comprising 2,588 patients with 10 different types of cancer were included in the study. Low sMICA/B levels were found associated with significantly longer OS (HR = 1.65, 95\% CI [1.42-1.92], $P<0.00001)$. Patients with cancers of digestive system that exhibited high MICA/B expression had significantly longer OS in (HR = 0.56, 95\% CI [0.39-0.80], $P=0.002)$ compared with those with lower MICA/B expression $\left(I^{2}=35 \%, P=0.18\right)$.

Conclusions: Serum soluble MICA/B represents a potential prognostic marker in various human cancers. High cell-surface MICA/B expression in cancers of the digestive system was found associated with increased survival.

\section{INTRODUCTION}

Identifying reliable prognostic biomarkers for cancer patients is a longstanding oncology research goal. To date, the majority of cancer prognosis biomarker findings have focused on cancer cell centric biomarkers, such as cancer cell gene mutations, miRNA and lncRNA secretions, and relative progression protein expressions [1-5]. However, cancer evolution is also greatly influenced by the immune system and complex milieu, indicating that biomarker research should also consider the impact of factors originating from outside of the tumor cells [6].

The MHC class I chain related-protein A (MICA) and $\mathrm{B}(\mathrm{MICB})$ are cancer cell-surface molecules that reflect both cancer cell-centric biological behavior and host immune status. The major histocompatibility complex
(MHC) class I chain related (MIC) gene family, which lies within the HLA region, consists of five members: MICA, MICB, MICC, MICD, and MICE. Of these five members, MICA and MICB are the only functional genes [7-9], which are frequently expressed by carcinomas of the breast, lung, colon, ovary, kidney, prostate, as well as in melanomas, gliomas, and leukemia $[10,11]$. MICA and $\mathrm{MICB}$, as signals of cellular stress, engage with natural killer group 2D (NKG2D). This engagement actives the cytolytic responses of $\gamma \delta \mathrm{T}$ cells and NK cells against epithelial tumor cells [12].

In addition to the membrane-bound form, a soluble isoform of MICA/B (sMICA/B) is present in the serum. This serum-soluble form is derived from the proteolytic shedding of the membrane bound molecule. MICA present on the surface forms a complex with a disulfide isomerase/ 
chaperone (ERp5). This complex induces a conformational change, enabling proteolytic cleavage of MICA by a disintegrin and metalloproteinase (ADAM) proteins [13].Then, the interaction of SMICA/B with NKG2D results in the endocytosis and degradation of receptorligand complexes and also suppresses NKG2D-mediated host cancer rejection $[14,15]$. Therefore, MICA/B and SMICA/B, reflecting the cancer cell centric biological behavior and tumor immune surveillance status, could be a potential prognostic biomarker of cancer patients.

Indeed, this correlation between expression of MICA/B and survival has been reported in a wide range of human carcinomas, including colorectal-, hepatocellular-, pancreatic-, gastric-, and lung carcinoma as well as melanoma [16-22]. However, some studies also report that high MICA/B expression is associated with unfavorable outcomes in ovarian cancer, non-small cell lung carcinoma, and breast cancer [23]. Previous studies have been carried out across many types of cancer, with widely different sample sizes and outcomes. It is still ambiguous whether the prognostic potential of MICA/B is attributable to the biologic properties of a specific cancer type, whether the prognosis value of MICA/B relies on their soluble isoform, and whether their prognosis effect depends on methodology differences.

Based on current knowledge, low level of sMICA/B in serum and high expression of MICA/B are expected to be associated with less immune escape and stronger cytolytic ability of effector cells, respectively[24-26]. And serum soluble $\mathrm{MICA} / \mathrm{B}$ and cancer cell-surface $\mathrm{MICA} / \mathrm{B}$ are detected by two different methods. At the same time, these up- or down- regulated molecules on cancer cell surface or in patient serum are all associated with patients' survival. Therefore, we conducted a systematic review and two meta-analysises to establish pooled estimates for survival outcomes based on sMICA/B serum levels and MICA/B cell surface expression in different types of cancers.

\section{RESULTS}

A total of 2,588 patients were included in the analysis, with the sample sizes ranging from 48 to 222 between the included studies, and the published years between 2007 and 2016. Of 171 citations, we identified 19 articles (Figure 1) encompassing 10 different cancer types that met the inclusion criteria, including cervical cancer, ovarian cancer, gastric cancer, cholangiocarcinoma, pancreatic cancer, hepatocellular carcinoma, oral squamous cell carcinoma(OSCC), lung carcinoma, melanoma, and multiple myeloma (Tables 1 and 2). Studies of soluble MICA/B comprised a total of 1,482 patients with 7 different types of carcinoma: non-small cell lung, cervical, pancreatic, oral squamous cell, hepatocellular carcinoma, melanoma, and multiple myeloma [27-32]. The largest number of studies focused on melanoma ( 5 studies, 628 patients).In the 10 immunohistochemistry (IHC) studies, we included 1,183 patients with 7 different types of carcinoma: non-small cell lung, cervical, ovarian, gastric, cholangiocarcinoma, pancreatic, and hepatocellular carcinoma $[17,19,27$, $33,34]$. The largest number of studies focused on nonsmall cell lung carcinoma (3 studies, 413 patients). Tissue expression of MICA/B was detected by immunohistochemical staining, and all serum sMICA/B studies were performed using ELISA. The NewcastleOttawa scale (NOS) confirmed that most of the studies were of high quality (Table 3 ).

\section{Prognostic effect of serum sMICA/B on OS in various cancer types}

Thirteen studies comprising 1,482 patients indicated a correlation between serum SMICA/B and OS. Meta-analysis of all these studies revealed a significant association between serum sMICA/B and survival, with higher sMICA/B in serum associated with a significantly lower OS rate, with a pooled HR of 1.65 (95\% CI [1.42$1.92], P<0.00001)$. The fixed-effects model was adopted to verify the significance of heterogeneity $\left(\mathrm{I}^{2}=45 \%, P\right.$ $=0.04$; Figure 2). Subgroup analyses were performed to evaluate the effects of various clinical variables on pooled OS (Table 4).

\section{Subgroup analysis of the prognostic effect of sMICA/B in different cancer subtypes}

Subgroup analyses and funnel plot of bias were implemented according to cancer type. According to our current included studies, we divided the cancer into three subtypes: digestive system cancers (hepatocellular carcinoma and pancreatic cancer), melanoma, and OSCC. Another two studies in multiple myeloma and non-small cell lung carcinoma were excluded in this subgroup analysis. High sMICA and sMICB levels were associated with significantly longer OS in various cancer types, including melanoma $(\mathrm{HR}=1.52,95 \% \mathrm{CI}[1.23-1.88], P$ $<0.0001)$, OSCC $(\mathrm{HR}=2.65,95 \%$ CI $[1.02-6.84], P=$ $0.04)$, and digestive system cancers $(\mathrm{HR}=1.70,95 \% \mathrm{CI}$ [1.35-2.13], $P<0.00001$; Supplementary Figure 1A, 1B).

\section{Subgroup analysis according to sMICA level and sMICB level}

Significant differences were found between the high level and low level of sMICA/B for cancer patient survival prognosis. For sMICA, the result showed that the pooled $\mathrm{HR}=1.60,95 \% \mathrm{CI}[1.37-1.87], P<0.00001$, with a heterogeneity analysis of $\mathrm{I}^{2}=47 \%, P=0.04$. For sMICB, HR $=2.86,95 \%$ CI [1.49-5.51], $P=0.002$ with heterogeneity analysis $\mathrm{I}^{2}=0 \%, P=0.78$ (Supplementary Figure 2A, 2B). These results suggested that, compared with sMICA, sMICB is a more reliable prognostic marker for patients with cancer. 
Table 1: Baseline characteristics for soluble MICA/B related studies included in meta-analysis

\begin{tabular}{|c|c|c|c|c|c|c|c|c|c|c|c|c|c|c|}
\hline Study & $\begin{array}{c}\text { Year of } \\
\text { publication }\end{array}$ & $\mathrm{MICA} / \mathrm{B}$ & Type of cancer & Country & $\begin{array}{c}\text { No. of } \\
\text { patients }\end{array}$ & $\begin{array}{c}\text { Cut-off point } \\
(\mathrm{pg} / \mathrm{ml})\end{array}$ & $\begin{array}{l}\text { Expression } \\
\text { (High:low) }\end{array}$ & Method & $\begin{array}{l}\text { Detective } \\
\text { system }\end{array}$ & $\begin{array}{c}\text { Median } \\
\text { duration of } \\
\text { follow up } \\
\text { (months) }\end{array}$ & $\begin{array}{l}\text { HR estimation } \\
\text { method }\end{array}$ & $\begin{array}{l}\text { Multivariable } \\
\text { analysis }\end{array}$ & $\begin{array}{l}\text { Hazard ratios } \\
(95 \% \text { CI })\end{array}$ & $P$-value \\
\hline Wang & 2015 & sMICA & $\begin{array}{l}\text { Non-small cell lung } \\
\text { cancer }\end{array}$ & China & 207 & 39.93 & $156: 51$ & ELISA & Roche & NA & Reported in the text & Yes & $2.39(1.30-4.98)$ & 0.002 \\
\hline Koguchi-1 & 2015 & SMICA & Melanoma & US & 124 & 247 & $31: 93$ & ELISA & R\&D Systems & 31 & Reported in the text & Yes & $1.75(1.02-3.01)$ & 0.042 \\
\hline Koguchi-2 & 2015 & SMICA & Melanoma & US & 123 & 247 & $26: 97$ & ELISA & $\mathrm{R} \& \mathrm{D}$ Systems & 31 & Reported in the text & Yes & $0.94(0.60-1.47)$ & 0.773 \\
\hline Koguchi-3 & 2015 & sMICA & Melanoma & Brazil & 48 & 247 & $28: 21$ & ELISA & R\&D Systems & 40 & Reported in the text & Yes & $1.48(0.67-3.28)$ & 0.328 \\
\hline $\mathbf{L i}$ & 2013 & sMICA & $\begin{array}{l}\text { Hepatocellular } \\
\text { carcinoma }\end{array}$ & China & 60 & 1000 & $28: 32$ & ELISA & Ancell & 32 & Reported in the text & Yes & $1.471(1.11-1.95)$ & 0.008 \\
\hline Wu & 2013 & sMICB & Melanoma & China & 125 & 7.92 & $64: 61$ & ELISA & R\&D Systems & NA & Data extrapolated & No & $2.78(1.40-5.51)$ & 0.004 \\
\hline Kumar-1 & 2012 & sMICA & $\begin{array}{l}\text { HBV-hepatocellular } \\
\text { carcinoma }\end{array}$ & Japan & 111 & 5 & $28: 83$ & ELISA & R\&D Systems & 67.1 & Data extrapolated & No & $3.88(1.18-12.77)$ & 0.026 \\
\hline Kumar-2 & 2012 & sMICA & $\begin{array}{l}\text { HCV-hepatocellular } \\
\text { carcinoma }\end{array}$ & Japan & 129 & 5 & 44:85 & ELISA & R\&D Systems & 67.1 & Data extrapolated & No & $0.91(0.39-2.09)$ & 0.8241 \\
\hline Duan & 2011 & sMICA & Pancreatic cancer & China & 77 & 290 & $33: 44$ & ELISA & R\&D Systems & 11.7 & Reported in the text & Yes & $3.96(2.52-7.96)$ & 0.004 \\
\hline Tamaki & 2010 & sMICB & $\begin{array}{l}\text { Oral squamous cell } \\
\text { carcinoma }\end{array}$ & Japan & 60 & 24 & $23: 37$ & ELISA & R\&D Systems & NA & Data extrapolated & No & $3.88(0.42-35.84)$ & 0.232 \\
\hline Paschen & 2009 & sMICA & Melanoma & Germany & 208 & 400 & NA & ELISA & R\&D Systems & 38.3 & Data extrapolated & No & $1.62(1.19-2.20)$ & 0.002 \\
\hline Tamaki & 2008 & sMICA & $\begin{array}{l}\text { Oral squamous cell } \\
\text { carcinoma }\end{array}$ & Japan & 113 & 50 & $41: 72$ & ELISA & R\&D Systems & NA & Data extrapolated & No & $2.43(0.85-6.94)$ & 0.098 \\
\hline Rebmann & 2007 & SMICA & Multiple myeloma & Germany & 97 & 305 & $59: 38$ & ELISA & IMMATICS & 53 & Reported in the text & Yes & $3.44(1.40-8.44)$ & 0.007 \\
\hline
\end{tabular}

Subgroup analysis according to multivariate correction and sample size

The association between $\mathrm{SMICA} / \mathrm{B}$ and OS was significant in studies with multivariate correction $(\mathrm{HR}=1.59$,
$95 \%$ CI [1.32-1.92], $P<0.00001)$ or univariate analysis (HR $=1.78,95 \%$ CI $[1.38-2.28], P<0.00001$; (Supplementary Figure 3A, 3B). The association between SMICA/B and OS was significant in studies with sample sizes both less than or equal to $100(\mathrm{HR}=1.70,95 \% \mathrm{CI}[1.33-2.17], P<0.0001)$

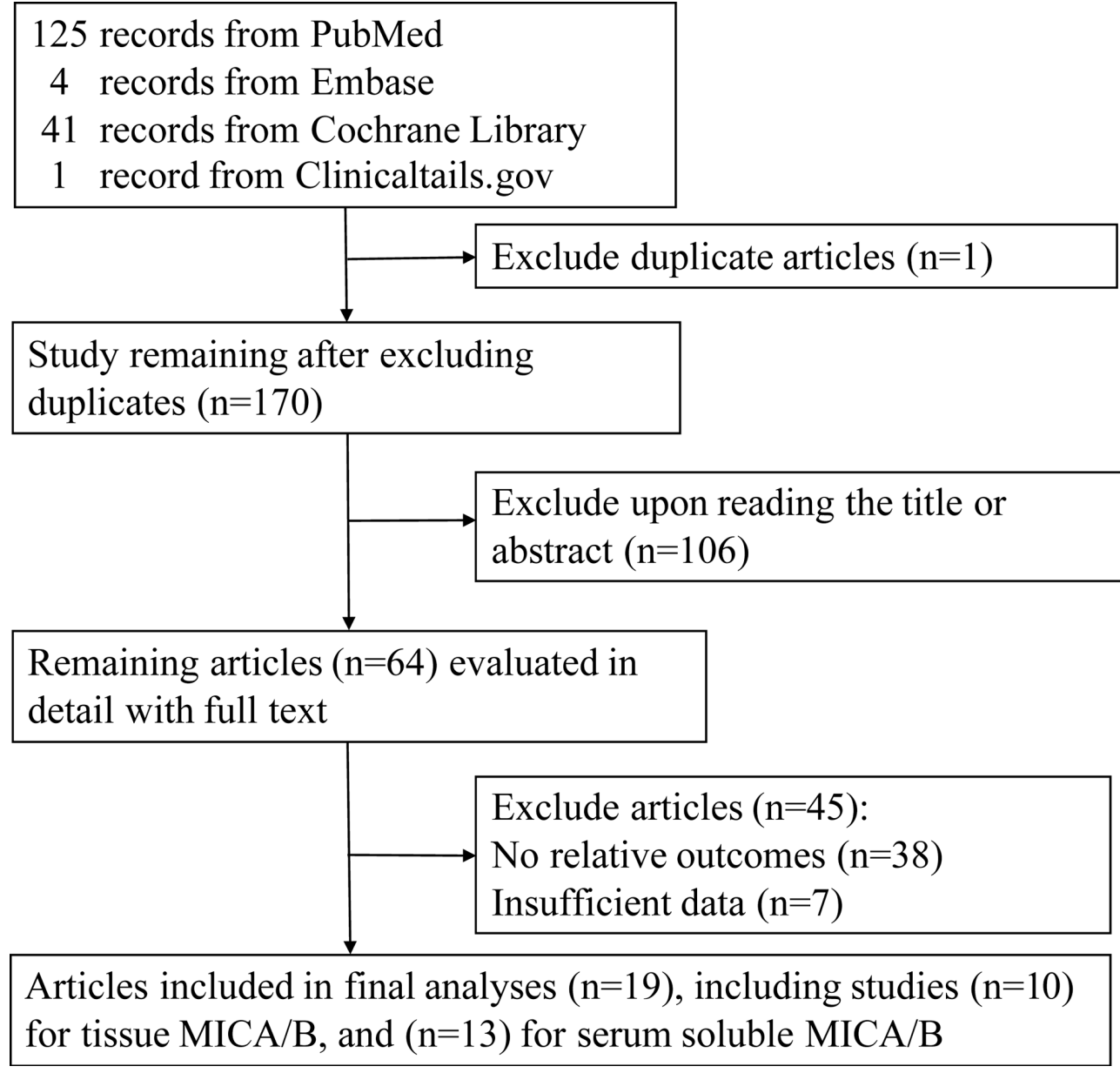

Figure 1: Flow diagram of search strategy and study selection. 
Table 2: Baseline characteristics for MICA/B related studies included in meta-analysis

\begin{tabular}{|c|c|c|c|c|c|c|c|c|c|c|c|c|c|c|c|}
\hline Study & $\begin{array}{c}\text { Year of } \\
\text { publication }\end{array}$ & $\mathrm{MICA} / \mathbf{B}$ & Type of cancer & Country & $\begin{array}{c}\text { No. of } \\
\text { patients }\end{array}$ & $\begin{array}{l}\text { cut off } \\
\text { point }\end{array}$ & $\begin{array}{l}\text { Expression } \\
\text { (High:Low) }\end{array}$ & Method & $\begin{array}{c}\text { IHC } \\
\text { antibody }\end{array}$ & $\begin{array}{l}\text { Antibody } \\
\text { dilution }\end{array}$ & $\begin{array}{c}\text { Median } \\
\text { duration of } \\
\text { follow up } \\
\text { (months) }\end{array}$ & $\begin{array}{l}\text { HR estimation } \\
\text { method }\end{array}$ & $\begin{array}{c}\text { Multivariable } \\
\text { analysis }\end{array}$ & Hazard ratios $(95 \% \mathrm{CI})$ & $P$-value \\
\hline Okita & 2016 & $\mathrm{MICA} / \mathrm{B}$ & $\begin{array}{l}\text { Non-small cell lung } \\
\text { cancer }\end{array}$ & Japan & 91 & $0-1,2-3$ & $28: 63$ & $\mathrm{IHC}$ & $\begin{array}{l}\text { Santa } \\
\text { Cruz }\end{array}$ & $1: 50$ & 41.4 & Reported in the text & Yes & $0.59(0.20-1.75)$ & 0.342 \\
\hline Tsukagoshi & 2016 & $\mathrm{MICA} / \mathrm{B}$ & Cholangiocarcinoma & Japan & 82 & $0-1,2$ & $67: 15$ & $\mathrm{IHC}$ & $\begin{array}{l}\text { Santa } \\
\text { Cruz }\end{array}$ & 1:800 & 16.5 & Reported in the text & Yes & $0.58(0.29-1.21)$ & 0.139 \\
\hline Chen & 2016 & MICA & Gastric cancer & China & 95 & $0-4,5-7$ & $38: 57$ & $\mathrm{IHC}$ & Abcam & $\mathrm{NA}$ & 47.4 & Reported in the text & Yes & $0.64(0.42-0.98)$ & 0.040 \\
\hline Zhao & 2016 & MICA/B & $\begin{array}{l}\text { Lung } \\
\text { adenocarcinoma }\end{array}$ & China & 100 & $0-4,5$ & $38: 62$ & $\mathrm{IHC}$ & Novus & 1:150 & 14.4 & Reported in the text & Yes & $3.39(2.04-7.36)$ & 0.001 \\
\hline Cho & 2014 & $\mathrm{MICA} / \mathrm{B}$ & Cervical cancer & Korea & 195 & $0-12$ & $112: 83$ & $\mathrm{IHC}$ & Novus & $1: 50$ & 169 & Reported in the text & No & $0.53(0.20-1.36)$ & 0.189 \\
\hline Zhang & 2014 & MICA & $\begin{array}{l}\text { Hepatocellular } \\
\text { carcinoma }\end{array}$ & China & 143 & $0-12$ & $64: 79$ & $\mathrm{IHC}$ & Abcam & $1: 100$ & 24 & Reported in the text & Yes & $0.91(0.49-1.69)$ & 0.774 \\
\hline Fang & 2014 & $\mathrm{MICA} / \mathrm{B}$ & $\begin{array}{l}\text { Hepatocellular } \\
\text { carcinoma }\end{array}$ & China & 96 & $0-12$ & $75: 21$ & $\mathrm{IHC}$ & Abgent & $1: 100$ & NA & Data extrapolated & No & $0.35(0.16-0.79)$ & 0.009 \\
\hline Chen & 2013 & MICA & $\begin{array}{l}\text { Non-small cell lung } \\
\text { cancer }\end{array}$ & China & 222 & $0-4,5-7$ & $84: 138$ & $\mathrm{IHC}$ & $\mathrm{NA}$ & $1: 25$ & 13 & Reported in the text & Yes & $3.08(1.52-6.25)$ & 0.002 \\
\hline Duan & 2011 & MICA & Pancreatic cancer & China & 77 & $0-1,2$ & $37: 40$ & $\mathrm{IHC}$ & $\begin{array}{l}\text { Santa } \\
\text { Cruz }\end{array}$ & $1: 100$ & 11.7 & Reported in the text & Yes & $0.29(0.12-0.72)$ & 0.007 \\
\hline $\mathbf{L i}$ & 2008 & $\mathrm{MICA} / \mathrm{B}$ & Ovarian cancer & Japan & 82 & $0-1,2$ & $42: 40$ & $\mathrm{IHC}$ & Biolegend & NA & 68.4 & Reported in the text & Yes & $1.36(0.54-3.45)$ & 0.513 \\
\hline
\end{tabular}

Table 3: Quality assessment of eligible studies (Newcastle-Ottawa scale)

\begin{tabular}{|c|c|c|c|c|c|c|c|c|c|}
\hline \multirow[b]{2}{*}{ Study } & \multicolumn{3}{|c|}{ Selection } & \multicolumn{3}{|c|}{ Comparability } & \multicolumn{2}{|c|}{ Outcome } & \multirow[b]{2}{*}{ Total } \\
\hline & $\begin{array}{l}\text { Adequacy of case } \\
\text { definition }\end{array}$ & $\begin{array}{c}\text { Number of } \\
\text { cases }\end{array}$ & $\begin{array}{l}\text { Representativeness } \\
\text { of the cases }\end{array}$ & $\begin{array}{l}\text { Ascertainment } \\
\text { of exposure }\end{array}$ & $\begin{array}{l}\text { Ascertainment of } \\
\text { detection method }\end{array}$ & $\begin{array}{l}\text { Ascertainment } \\
\text { of cut-off }\end{array}$ & $\begin{array}{c}\text { Assessment of } \\
\text { outcome }\end{array}$ & $\begin{array}{l}\text { Adequate } \\
\text { follow up }\end{array}$ & \\
\hline Okita 2016 & 1 & 1 & 1 & 1 & 1 & 1 & 1 & 1 & 8 \\
\hline Tsukagoshi 2016 & 1 & 1 & 1 & 1 & 1 & 1 & 1 & 1 & 8 \\
\hline Zhao 2016 & 1 & 1 & 1 & 1 & 1 & 1 & 1 & 1 & 8 \\
\hline Chen 2016 & 1 & 1 & 1 & 1 & 1 & 1 & 1 & 1 & 8 \\
\hline Koguchi 2015 & 1 & 1 & 1 & 1 & 1 & 1 & 1 & 1 & 8 \\
\hline Wang 2015 & 0 & 1 & 1 & 1 & 1 & 0 & 1 & 1 & 6 \\
\hline Cho 2014 & 1 & 1 & 1 & 1 & 1 & 1 & 1 & 1 & 8 \\
\hline Fang 2014 & 1 & 1 & 1 & 1 & 1 & 1 & 1 & 0 & 7 \\
\hline Zhang 2014 & 1 & 1 & 1 & 1 & 1 & 1 & 1 & 1 & 8 \\
\hline Chen 2013 & 1 & 1 & 1 & 1 & 1 & 1 & 1 & 1 & 8 \\
\hline Li 2013 & 1 & 1 & 1 & 1 & 1 & 1 & 1 & 1 & 8 \\
\hline Wu 2013 & 1 & 1 & 1 & 1 & 1 & 1 & 1 & 0 & 7 \\
\hline Kumar 2012 & 1 & 1 & 1 & 0 & 1 & 1 & 1 & 1 & 7 \\
\hline Duan 2011 & 0 & 1 & 1 & 1 & 1 & 1 & 1 & 0 & 6 \\
\hline Tamaki 2010 & 1 & 1 & 1 & 1 & 1 & 1 & 1 & 0 & 7 \\
\hline Paschen 2009 & 1 & 1 & 1 & 1 & 1 & 1 & 1 & 1 & 8 \\
\hline Tamaki 2008 & 1 & 1 & 1 & 1 & 1 & 1 & 1 & 0 & 7 \\
\hline Li 2008 & 1 & 1 & 1 & 1 & 1 & 1 & 1 & 0 & 7 \\
\hline Rebmann 2007 & 1 & 1 & 1 & 1 & 1 & 1 & 1 & 1 & 8 \\
\hline
\end{tabular}

and more than $100(\mathrm{HR}=1.63,95 \%$ CI [1.34-1.97], $P<$ 0.00001; Supplementary Figure 4A, 4B).

\section{The prognostic effect of MICA/B expression on $O S$ in various cancer types}

OS was reported in 10 studies of $\mathrm{MICA} / \mathrm{B}$ expression in a total of 1,183 cancer patients. The meta-analysis of all these studies revealed a significant association between MICA/B expression and OS. No statistically significant association was observed between high MICA/B expression and longer OS $(\mathrm{HR}=0.85,(95 \%$ CI [0.49-1.48], $P=0.58)$. The random-effects model was adopted to determine the significance of heterogeneity $\left(\mathrm{I}^{2}=84 \%, P<0.00001 ;\right.$ Figure 3$)$.

\section{Subgroup analysis of the prognostic effect of $\mathrm{MICA} / \mathrm{B}$ expression in different cancer subtypes}

Table 5 shows the results of meta-analyses of OS for each subgroup analysis. We divided the cancer types into 3 categories: digestive system cancer (including:cholangiocarcinoma, gastric cancer, hepatocellular carcinoma, pancreatic cancer), respiration system cancer (including:lung adenocarcinoma, and nonsmall cell lung carcinoma), and gynecologic malignant tumors (including: ovarian cancer and cervical cancer). High MICA expression was associated with significantly longer OS in cancers of the digestive system ( $\mathrm{HR}=0.56$, $95 \%$ CI [0.39-0.80], $P=0.002 ; I^{2}=35 \%$ ), non-small cell lung carcinoma $(\mathrm{HR}=2.06,95 \% \mathrm{CI}[0.86-4.94], P=$ 
Table 4: Subgroup analysis of the prognostic significance of soluble MICA/B

\begin{tabular}{|c|c|c|c|c|c|c|}
\hline & Number of studies & Number of patients & HR 95\%CI & Overall effect $P$-value & $\begin{array}{c}\text { Subgroup differences } \\
P \text {-value }\end{array}$ & $I^{2}$ \\
\hline Cancer type & & & & & 0.47 & \\
\hline Melanoma & 5 & 628 & $1.52(1.23-1.88)$ & $<0.0001$ & & $49 \%$ \\
\hline OSCC & 2 & 173 & $2.65(1.02-6.84)$ & 0.04 & & $0 \%$ \\
\hline Digestive system cancers & 5 & 377 & $1.70(1.35-2.13)$ & $<0.00001$ & & $58 \%$ \\
\hline ELISA & & & & & 0.09 & \\
\hline sMICA & 11 & 1297 & $1.60(1.37-1.87)$ & $<0.00001$ & & $47 \%$ \\
\hline sMICB & 2 & 185 & $2.86(1.49-5.51)$ & 0.002 & & $0 \%$ \\
\hline Multivariate correction & & & & & 0.48 & \\
\hline Yes & 7 & 736 & $1.59(1.32-1.92)$ & $<0.00001$ & & $58 \%$ \\
\hline No & 6 & 746 & $1.78(1.38-2.28)$ & $<0.00001$ & & $28 \%$ \\
\hline Sample size & 5 & & & & 0.79 & \\
\hline$\leq 100$ & 5 & 342 & $1.70(1.33-2.17)$ & $<0.0001$ & & $44 \%$ \\
\hline$>100$ & 8 & 1140 & $1.63(1.34-1.97)$ & $<0.00001$ & & $52 \%$ \\
\hline
\end{tabular}

$0.10 ; \mathrm{I}^{2}=76 \%$ ), and gynecologic malignant tumors (HR $=0.85,95 \%$ CI [0.34-2.15], $P=0.74 ; \mathrm{I}^{2}=49 \%$ ). There was a significant difference between subgroups by cancer types $\left(P=0.02, \mathrm{I}^{2}=73.5 \%\right)$. These results suggested that the prognostic effect of MICA/B expression for cancers of the digestive system was more powerful than that for the other cancer types. MICA/B expression level may not be a useful prognostic indicator in gynecologic malignant tumors and non-small cell lung carcinoma (Supplementary Figure 5A, 5B)

\section{Subgroup analysis according to MICA or MICA/B expression}

Among the 10 studies, 6 of them reported detection of MICA and MICB together, while 4 reported the detection of MICA only. High MICA/B expression was not significantly associated with longer OS ( $\mathrm{HR}=0.84$, $95 \%$ CI [0.36-1.93], $P=0.68$ ), and the pooled results from MICA did not reveal a significant association with OS
$(\mathrm{HR}=0.87,95 \% \mathrm{CI}[0.38-1.96], P=0.73$; Supplementary Figure 6A, 6B).

\section{Subgroup analysis according to multivariate correction and sample size}

We next investigated whether heterogeneity resulted from the difference in statistical methods used between studies. The results of multivariate adjusted analysis for OS were reported in 8 studies; however, in the other 2 studies, 1 study was data extrapolated and 1 was from a univariate analysis. High MICA expression was associated with significantly longer OS in the univariate analysis subgroup (HR $=0.41,95 \%$ CI $[0.23-0.76], P=0.004)$. However, there was no statistically significant effect observed in the multivariate analysis subgroup $(\mathrm{HR}=1.01,95 \% \mathrm{CI}[0.54$ 1.86], $P=0.99)$. This result indicated that multivariate analysis or univariate analysis did not represent the major sources of heterogeneity (Supplementary Figure 7A, 7B). We further divided the 10 studies based on large sample

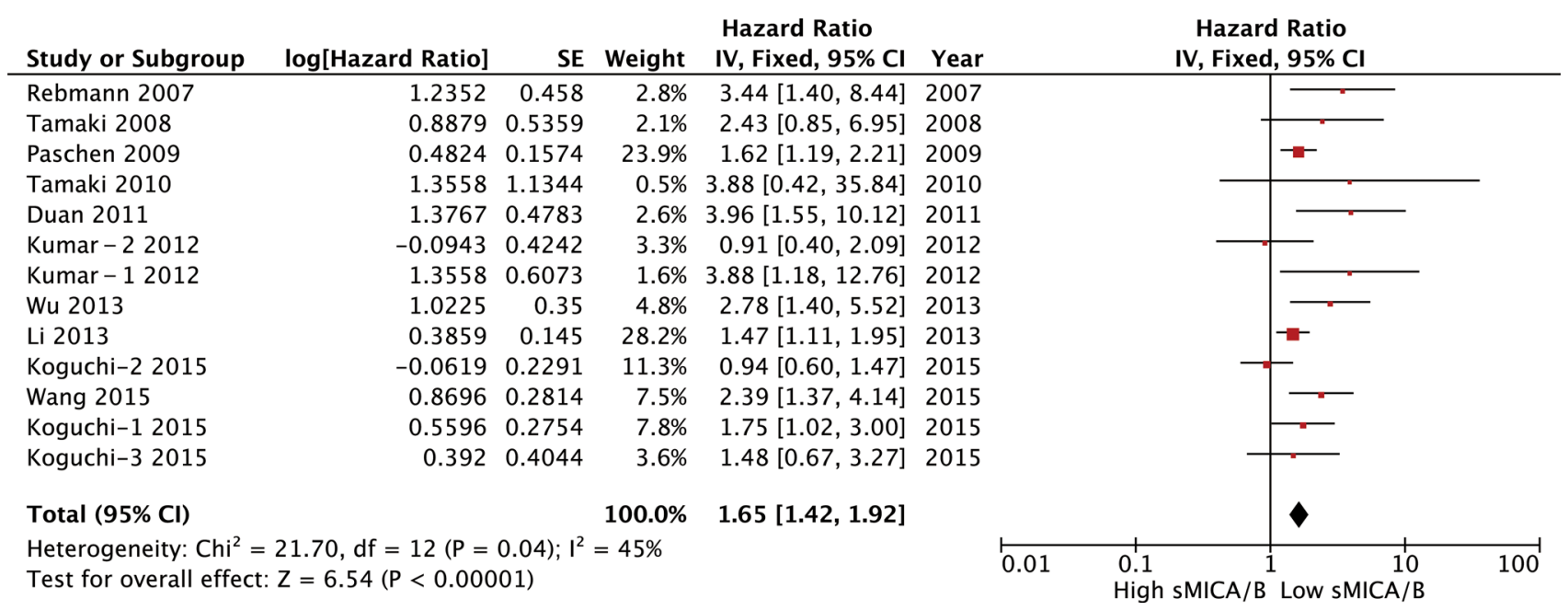

Figure 2: Forest plot for the association between soluble MICA/B levels with prognosis. 
size $(n>100)$ or small sample size $(n \leq 100)$. Subgroup analysis indicated no statistically significant association between MICA/B and survival for either the subgroup with the small sample size (HR $=0.74,95 \%$ CI $[0.37-1.50]$, $P=0.41)$ or that with the large sample size $(\mathrm{HR}=1.18$, $95 \%$ CI [0.44-3.15], $P=0.74)$. These results indicated that heterogeneity were not from sample size (Supplementary Figure 8A, 8B).

\section{Publication bias and sensitivity analysis}

The publication bias of the present meta-analysis was evaluated by funnel plot. The shape of the funnel plot was almost symmetrical. To test the stability of metaanalysis of sMICA/B and OS, we performed a sensitivity analysis by sequentially removing each eligible study. And the present meta-sensitivity analysis did not suggest an undue influence of any single study (Figures 4, 5 and 6).

\section{DISCUSSION}

To our our knowledge, the present meta-analysis is the first to comprehensively evaluate the association of immune effector molecule expression (MICA/B) and serum shedding immune effector molecules (sMICA/B) with prognosis in variable types of cancer. Our metaanalysis reviewed a total of 19 studies comprising 2,588 patients to determine the prognositic value of MICA/B and sMICA/B in 10 types of cancer. The overall pooled analysis of all types of cancer suggested that a high level of soluble MICA/B in serum was associated with poor OS, with no significant difference between cancer types. With regards to MICA/B expression as detected by IHC, high MICA/B expression level was associated with longer survival in cancers of the digestive system. However, no statistical significance was observed for $\mathrm{MICA} / \mathrm{B}$ expression level when all types of cancer were considered. A high level of sMICA/B in serum had a negative prognostic effect on cancer patients. This finding suggested that shedding of NKG2D ligands by cancer cells enable these cells to evade the immune response by escaping detection by NK cells, $\gamma \delta$ T cells and CD8+ $\mathrm{T}$ cells. Conversely, a high MICA/B expression was associated with a favorable outcome in cancers of the digestive system, supporting the notion that MICA/B is a critical ligand in immune cytotoxicity.

In serum, we observed that $\mathrm{sMICA} / \mathrm{B}$ was an independent prognosis factor in cancer patients, with moderate heterogeneity. There were no significant differences in various type of cancers. Further, no significant heterogeneity was observed between SMICA and sMICB. Soluble MICA/B was a more reliable prognostic indicator compared with $\mathrm{MICA} / \mathrm{B}$ cell surface expression, as the former is easier to detect and the results are less affected by individual estimates. To detect MICA/B expression in cacner cell surface, biopsies are necessary; however, cancerous sites are not always reachable. Moreover, not all patients with cancer are tolerant of biopsy. These factors decrease the feasibility of MICA/B detection by IHC. Therefore, soluble MICA/B in serum is more applicable in such situations. Furthermore, the interpretation of immunohistochemical staining is influenced by individual subjective factors, and results are more difficult to quantify. Overall, sMICA/B are more advantaged at cancer patient survival prognosis.

Unlike previous studies that have focused on cancer cell-centric prognosis biomarkers, such as microRNA, IncRNA, or relative progression proteins, the present meta-analysis focused on biomarkers associated with immune cell interaction $[3,35,36]$. Immune effector molecules MICA/B not only reflect a distinct underlying biology of the tumor, but they are also involved in innate immune activation and cancer immune tolerance [6]. Of the adoptive immunotherapeutic strategies, $\mathrm{MICA} / \mathrm{B}$ or soluble $\mathrm{MICA} / \mathrm{B}$ could be a reflection of a pre-existing immune con-texture and of the immune response to NK cell-, T cell-, and $\gamma \delta \mathrm{T}$ cell-based immunotherapy. Studies of cytokine-induced killer cell (CIK) therapy have reported that cancer patients with high MICA expression experienced a significantly greater survival benefit from

\begin{tabular}{|c|c|c|c|c|c|c|c|c|c|}
\hline Study or Subgroup & log[Hazard Ratio] & SE & Weight & $\begin{array}{c}\text { Hazard Ratio } \\
\text { IV, Random, } 95 \% \mathrm{CI}\end{array}$ & Year & & $\begin{array}{r}\text { Hazard } \\
\text { IV, Randor }\end{array}$ & $\begin{array}{l}\text { d Ratio } \\
\mathrm{m}, \mathbf{9 5 \%} \mathrm{Cl}\end{array}$ & \\
\hline Li 2008 & 0.3092 & 0.4733 & $9.2 \%$ & $1.36[0.54,3.44]$ & 2008 & & & & \\
\hline Duan 2011 & -1.2351 & 0.458 & $9.3 \%$ & $0.29[0.12,0.71]$ & 2011 & & & & \\
\hline Chen 2013 & 1.1249 & 0.3603 & $10.3 \%$ & $3.08[1.52,6.24]$ & 2013 & & & & \\
\hline Zhang 2014 & -0.0898 & 0.3128 & $10.7 \%$ & $0.91[0.50,1.69]$ & 2014 & & & & \\
\hline Cho 2014 & -0.6349 & 0.4809 & $9.1 \%$ & $0.53[0.21,1.36]$ & 2014 & & & - & \\
\hline Fang 2014 & -1.0498 & 0.3994 & $9.9 \%$ & $0.35[0.16,0.77]$ & 2014 & & & & \\
\hline Okita 2016 & -0.5259 & 0.5528 & $8.4 \%$ & $0.59[0.20,1.75]$ & 2016 & & & & \\
\hline Zhao 2016 & 1.2199 & 0.2587 & $11.2 \%$ & $3.39[2.04,5.62]$ & 2016 & & & $\longrightarrow$ & \\
\hline Tsukagoshi 2016 & -0.5447 & 0.3537 & $10.4 \%$ & $0.58[0.29,1.16]$ & 2016 & & & & \\
\hline Chen 2016 & -0.4427 & 0.2156 & $11.5 \%$ & $0.64[0.42,0.98]$ & 2016 & & & & \\
\hline Total $(95 \% \mathrm{Cl})$ & & & $100.0 \%$ & $0.85[0.49,1.48]$ & & & & & \\
\hline \multicolumn{6}{|c|}{$\begin{array}{l}\text { Heterogeneity: } \mathrm{Tau}^{2}=0.64 ; \mathrm{Chi}^{2}=55.77, \mathrm{df}=9(\mathrm{P}<0.00001) ; \mathrm{I}^{2}=84 \% \\
\text { Test for overall effect: } \mathrm{Z}=0.56(\mathrm{P}=0.58)\end{array}$} & 0.01 & 0.1 High MICA/B & Low MICA/B & 100 \\
\hline
\end{tabular}

Figure 3: Forest plot for the association between MICA/B expression levels with prognosis. 
Table 5: Subgroup analysis of the prognostic significance of MICA/B

\begin{tabular}{|c|c|c|c|c|c|c|}
\hline & Number of studies & Number of patients & HR $95 \%$ CI & Overall effect $P$-value & $\begin{array}{l}\text { subgroup differences } \\
P \text {-value }\end{array}$ & $I^{2}$ \\
\hline Cancer type & & & & & 0.02 & \\
\hline Respiratory system cancers & 3 & 413 & $2.06(0.86-4.94)$ & 0.10 & & $76 \%$ \\
\hline Digestive system cancers & 5 & 493 & $0.56(0.39-0.80)$ & 0.002 & & $35 \%$ \\
\hline Gynecologic cancers & 2 & 277 & $0.85(0.34-2.15)$ & 0.74 & & $49 \%$ \\
\hline Multivariate correction & & & & & 0.04 & \\
\hline Yes & 8 & 892 & $1.01(0.54-1.86)$ & 0.99 & & $85 \%$ \\
\hline No & 2 & 291 & $0.41(0.23-0.76)$ & 0.004 & & $0 \%$ \\
\hline Antibody & & & & & 0.95 & \\
\hline MICA & 4 & 537 & $0.87(0.38-1.96)$ & 0.73 & & $85 \%$ \\
\hline MICA/B & 6 & 646 & $0.84(0.36-1.93)$ & 0.68 & & $85 \%$ \\
\hline Sample size & & & & & 0.45 & \\
\hline$\leq 100$ & 7 & 623 & $0.74(0.37-1.50)$ & 0.41 & & $86 \%$ \\
\hline$>100$ & 3 & 560 & $1.18(0.44-3.15)$ & 0.74 & & $80 \%$ \\
\hline
\end{tabular}

CIK treatment $[19,21]$. Therefore, prognostic markers MICA/B and sMICA/B may additionally serve as predictors of treatment outcomes in patients receiving immunotherapies.

No significant statistical difference was observed for the association between MICA/B expression and survival in all types of cancer. Subgroup analysis was conducted to explore the data further. We found that in respiratory and gynecologic malignant tumors, there was no evidence showing that MICA/B expression was associated with cancer outcome. However, the association between MICA/B expression and survival was significant for digestive system cancers $(P=0.002)$. The reasons underlying these inconsistent results may be manifold: it is speculated that in respiratory cancers and gynecologic malignant tumors, dedifferentiation results in the expression of MICA; however, in the absence of other pro-inflammatory signals, there was no infiltration of

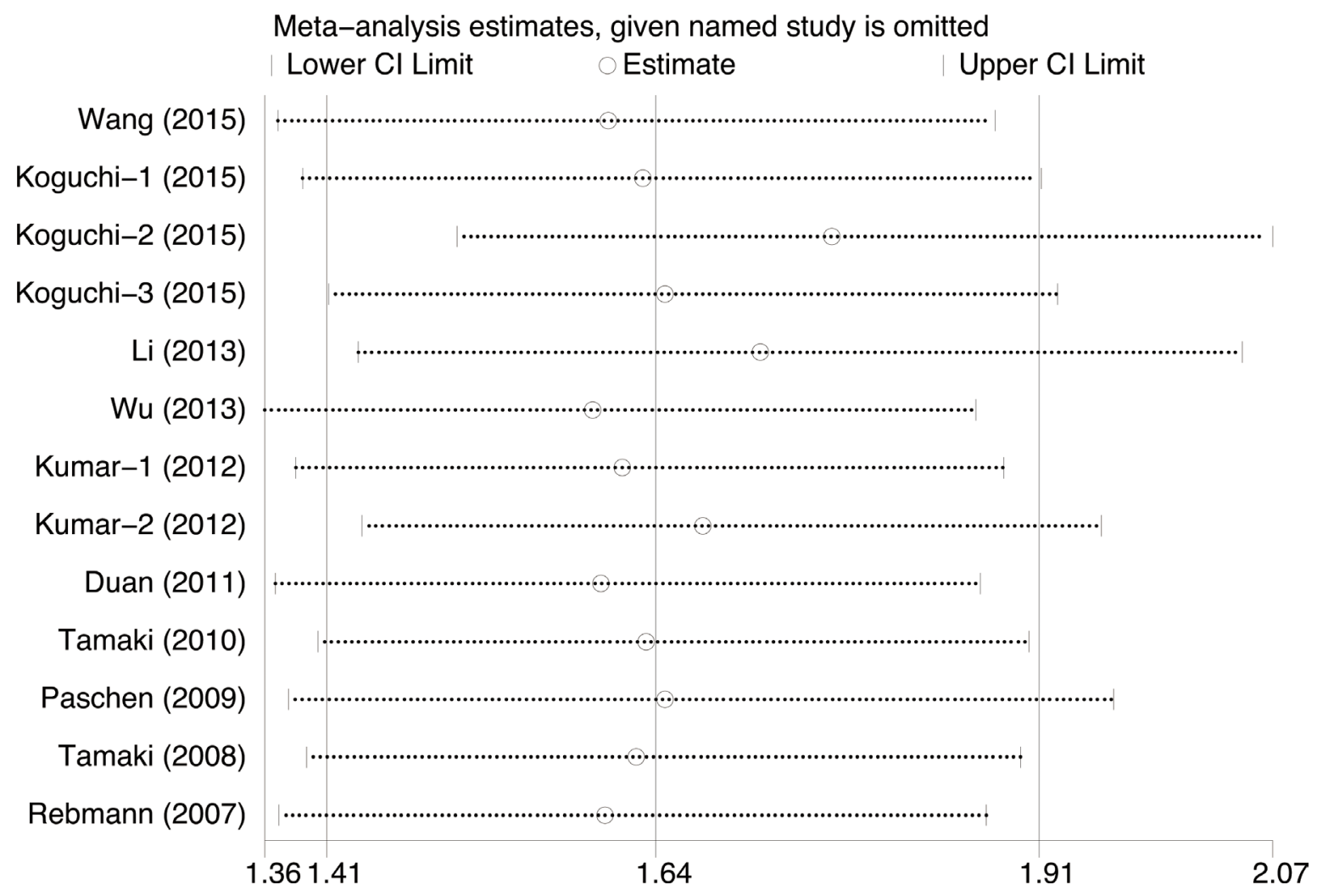

Figure 4: Sensitivity analysis for soluble MICA/B to estimate the impact of individual studies on the results of the meta-analysis. 
immune effector cells. Therefore, MICA expression had no influence on cancer survival in these cancer types. This has been observed in ovarian cancer, where high expression of MICA/B significantly correlated with lower degree of NK cells intra-epithelial infiltration [37]. In our studies, IHC data indicated a large proportion of cytoplasmic MICA/B expression instead of cell surface staining in lung cancers and gynecologic malignant tumors. This phenomenon was also reported by another two studies in clear cell renal cell carcinoma and breast cancer $[23,38]$. However, a widely accepted theory is that MICA/B expressed on the cell surface, but not in the cytoplasm, interacts with NKG2D receptors on NK cells, $\gamma \delta \mathrm{T}$ cells, and T cells [39]. Alternatively, MICA/B expressed only within the cytoplasm results in the immune evasion by the cancer cell and limited survival for the patient, instead of cytoplasm.

There is no international unification measurement to determine levels of MICA/B, and MICA/B localisation is also not assessed in a standardized manner. In the included studies present in the present analysis, three major evaluation criteria were applied: the expression score was calculated by multiplying the intensity and positivity scores [27], or by adding these scores [19, $21]$, and the third criterion was evaluated according to staining intensity [33]. The heterogeneity associated with the evaluation criteria and cut-off point made the metaanalysis of MICA/B expression by IHC challenging.

Further, the current meta-analysis has several potential limitations: firstly, various factors such as heterogeneity in $\mathrm{MICA} / \mathrm{B}$ expression IHC scoring strategies, cut-off points, and cancer stages restricted us from obtaining more comprehensive results. As the prognostic role of MICA/B seems to be substantially different according to cancer site, the overall pooled analysis of all types of cancer may have been highly dependent on the relative proportion of each specific type of cancer. Furthermore, in several studies, HR for outcome measures were derived from Kaplan-Meier survival curves when not provided by the original studies directly, and a few of the studies provided an inconsistent HR, 95\% CI, and $P$-value. These inconsistencies were considered to have affected the level of evidence. These limitations mandate caution when interpreting the present results.

In conclusion, despite the limitations described above, the current meta-analysis provides evidence that sMICA/B levels serve as a reliable prognostic marker in various cancers. The expression levels of $\mathrm{MICA} / \mathrm{B}$ on cancer cell surface were significantly associated with OS in patients with digestive system cancer. In addition to prognostic utility, an improved understanding of MICA/B in various cancers types should enable the development of more precise and effective immunotherapies.

\section{MATERIALS AND METHODS}

\section{Search strategy and selection criteria}

We conducted and reported this systematic review and meta-analysis in accordance with the PRISMA

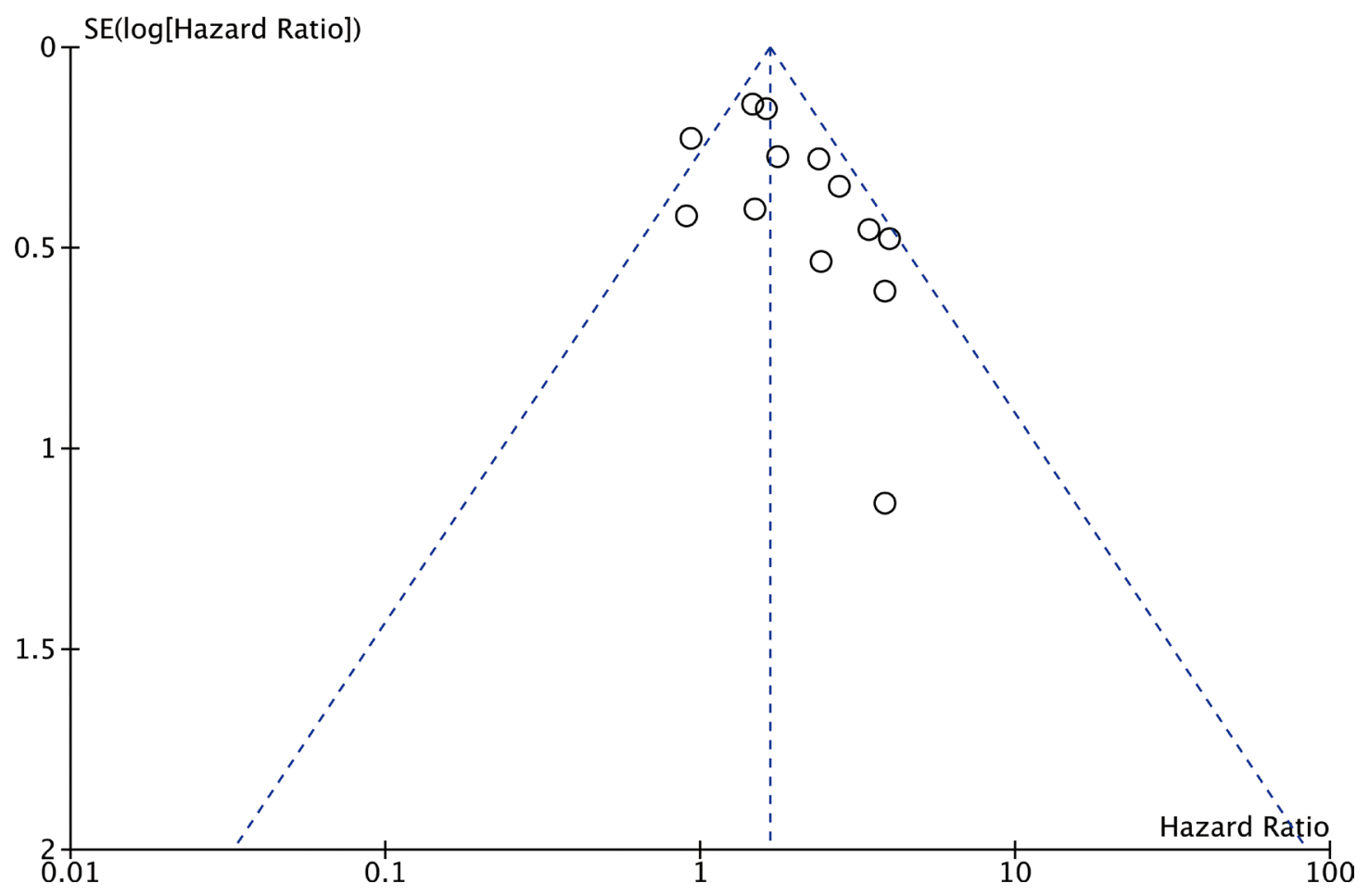

Figure 5: Funnel plot of the bias for the analysis of the independent role of soluble MICA/B in OS in the different cancer types. 
statement. We systematically searched PubMed, Embase, Clinicaltrails.gov, and Cochrane Library(up to July 15, 2017), without language restrictions, for human studies of the prognostic significance of MICA/B and sMICA/B in cancer. The following keywords were used for the search: ("Prognosis" OR "Mortality" OR "Survival") AND ("MICA" OR "MICB" OR "MIC" OR "MICA/B" OR "MICA-B" OR "MHC class I-related chain A" OR "MHC class I chain related gene A protein" OR "MHC class I chain-related protein B" OR "MHC class I chainrelated antigen B") AND ("Neoplasia" OR "Neoplasias" OR "Neoplasm" OR "Tumors" OR "Tumor" OR "Malignancy" OR "Malignancies" OR "Cancer" OR "Cancers" OR "Neoplasms"). We scrutinized the reference lists of the identified reports, reviews, meta-analyses, and other relevant publications to indentify additional pertinent studies.

\section{Inclusion and exclusion criteria}

Studies that met the following criteria were included in the meta-analysis: studies must have: (1) been published as original articles; (2) evaluated human subjects; (3) evaluated MICA, MICB or MICA/B in cancer surgical specimens using immunohistochemical method or any other method, or sMICA or sMICB in serum by ELISA and any other method; (4) reported association of high and low MICA/B expression with overall survival (OS); (5) reported association of high and low SMICA/B with OS; and (6) contained the minimum information necessary to estimate the effects (i.e., hazard ratio) and a corresponding measure of uncertainty (i.e., confidence interval, $P$-values, standard errors or variance). As an additional criterion, when a single population was reported in multiple reports, only the report with the most complete data was included to avoid duplication. Further, when a single report contained more than one unduplicated studies, all of the studies that met the inclusion criteria were included, and these studies were named by author and number. In this review, we additionally included studies that did not distinguish between MICA and MICB by immunohistochemistry, as the MICA and MICB locus encode the proteins of the same size with $83 \%$ similar amino acid sequence, and no distinct functions relating to cancer immune response have been found [40]. The eligibility of each study was assessed independently by two investigators (YJ.Z and NF.C). We excluded studies that were not published as full reports, such as conference abstracts and letters to editors, as well as studies that did not report sufficient data for the estimation of survival rates.

\section{Assessment of risk of bias}

We used the NOS to assess the risk of bias [41]. The NOS evaluates a high quality study in three domains: selection of participants, comparability of study groups, and the ascertainment of outcomes of interest. We considered studies that received a score of seven or more than that as low risk of bias, and those that scored less than seven as high risk of bias. This cut-off point was chosen according to the distribution of relative quality scores of all included studies.

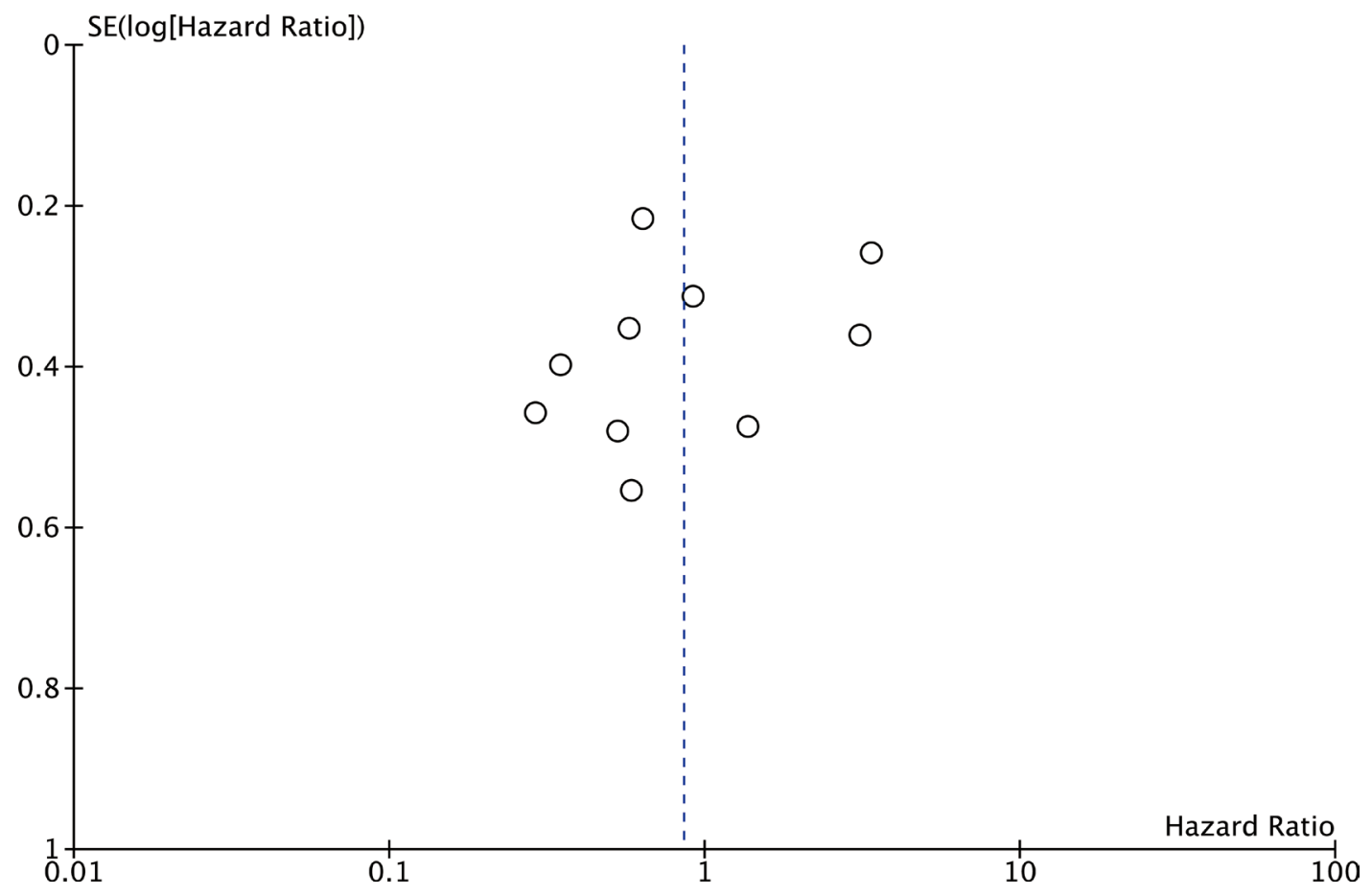

Figure 6: Funnel plot of the bias for the analysis of the independent role of MICA/B in OS in the different cancer types. 


\section{Data extraction}

Two investigators (YJ.Z and NF.C) independently summarized the studies meeting the inclusion criteria and performed data extraction using a predefined form, recording: author, year of publication, MICA or MICB or sMICA or sMICB, sample size, cancer type, median follow-up time, country, scoring protocols to identify $\mathrm{MICA} / \mathrm{B}$ expression, cut-off point to identify sMICA/B, expression (High: Low), method of study, outcome of univariate and/or multivariate analysis (including $P$-values, hazard ratios [HR], and 95\% confidence intervals $[\mathrm{CI}]$ ).

\section{Indices}

The endpoint used in this meta-analysis was OS. For MICA/B, study-defined binary variables indicating either the presence (versus absence), positive (versus negative), or high (versus low) expression were used and described as "high" or "low" MICA/B expression. For sMICA/B in serum, study-defined binary variables indicating either more (versus less) or high (versus low) were also described as "high" or "low" level.

\section{Statistical analyses}

The present meta-analysis and statistical analyses were using Revman software (version 5.3; Cochrane Collaboration, Oxford, United Kingdom). HR and its 95\% $\mathrm{CI}$ were used to estimate the association between MICA/B and prognosis. For sensitivity analysis, we used Stata software (version 14.2;STATA Corp., College Station, TX, USA). If results of both univariate and multivariate Cox regression analyses were reported, we used estimates from the multivariate Cox regression model for a more direct estimate of the effect of MICA after controlling for potential confounding variables. If a direct reported of HR and $95 \%$ CI were not available, survival data from Kaplan-Meier curves were read using Engauge Digitizer version 9.7 (http://digitizer.sourceforge.net/) as described previously. The calculation method for HR was based on Tierney's protocol $[42,43]$. This work was performed by two independent reviewers (YJ.Z and NF.C) to reduce inaccuracy in the extracted survival rates.

We assessed heterogeneity between studies with the $I^{2}$ statistic as a measure of the proportion of total variation in estimates due to heterogeneity, where $\mathrm{I}^{2}$ values of $25 \%$, $50 \%$, and $75 \%$ corresponded to cut-off points for low, moderate, and high degrees of heterogeneity. Subgroup analyses were carried out to investigate potential sources of heterogeneity. Sensitive analysis conducted to assess whether conclusions were sensitive to restricted studies. Subgroups were defined according to different types of cancer, sample sizes, multivariate correction, and whether MICA or MICB were assessed together or individually. Tests for the effects of subgroup interaction were performed.

\section{Abbreviations}

ADAM: A disintegrin and metalloproteinase; CI: Confidence interval; HR:Hazard ratio; MHC: Major histocompatibility complex; MICA: MHC class I polypeptide-related sequence A; MICB: $\mathrm{MHC}$ class I polypeptide-related sequence B; NKG2D: Natural killer group 2D; OS: Overall survival; OSCC: Oral squamous cell carcinoma; sMICA: Soluble MHC class I polypeptide-related sequence A; sMICB: Soluble MHC class I polypeptide-related sequence B; IHC: Immunohistochemistry

\section{Author contributions}

JW.C and YJ.Z conceived of and designed the study; YJ.Z, and NF.C extracted the data; YJ.Z and NF.C analysed the data; NF.C and Y.Y contributed materials/ analysis tools; YJ.Z and NF.C wrote and revised the manuscript. LL.Z, FJ.H, HM.T, YD.L, Z.L, C.N and JW.C revised the manuscript.All authors reviewed and approved the manuscript prior to submission.

\section{ACKNOWLEDGMENTS}

Not applicable.

\section{CONFLICTS OF INTEREST}

The authors declare no conflicts of interest.

\section{FUNDING}

This work was supported by grants from the Nation Key Research and Development Program of China (Grant No. 2016YFC1303800), the Key Laboratory Construction Project of Science and Technology Department (Grant No. 20170622011JC), the Industrial Research and Development Project of Development and Reform Commission of Jilin Province (Grant No. 2017C022), the Project of Development and Reform Commission of Jilin Province (Grant No. 2014N147), Science and Technology Department of Natural Science Fund Project in Jilin Province (Grant No.20150101176JC) to JWC.

\section{REFERENCES}

1. Zhang M, Li G, Wang Y, Wang Y, Zhao S, Haihong P, Zhao H, Wang Y. PD-L1 expression in lung cancer and its correlation with driver mutations: a meta-analysis. Sci Rep. 2017; 7:10255.

2. Xie Y, Ma X, Chen L, Li H, Gu L, Gao Y, Zhang Y, Li X, Fan Y, Chen J, Zhang X. MicroRNAs with prognostic significance in bladder cancer: a systematic review and meta-analysis. Sci Rep. 2017; 7:5619. 
3. Cheng D, Qiu X, Zhuang M, Zhu C, Zou H, Liu Z. MicroRNAs with prognostic significance in osteosarcoma: a systemic review and meta-analysis. Oncotarget. 2017; 8:81062-74. https://doi.org/10.18632/oncotarget.19009.

4. Wang D, Chen Z, Xu H, He A, Liu Y, Huang W. Long noncoding RNA CCAT2 as a novel biomaker of metastasis and prognosis in human cancer: a meta-analysis. Oncotarget. 2017; 8:75664-74. https://doi.org/10.18632/ oncotarget.18161.

5. Li X, Ma X, Chen L, Gu L, Zhang Y, Zhang F, Ouyang Y, Gao Y, Huang Q, Zhang X. Prognostic value of CD44 expression in renal cell carcinoma: a systematic review and meta-analysis. Sci Rep. 2015; 5:13157.

6. Angell H, Galon J. From the immune contexture to the Immunoscore: the role of prognostic and predictive immune markers in cancer. Curr Opin Immunol. 2013; 25:261-267.

7. Fodil N, Laloux L, Wanner V, Pellet P, Hauptmann G, Mizuki N, Inoko H, Spies T, Theodorou I, Bahram S. Allelic repertoire of the human MHC class I MICA gene. Immunogenetics. 1996; 44:351-357.

8. Bahram S, Mizuki N, Inoko H, Spies T. Nucleotide sequence of the human MHC class I MICA gene. Immunogenetics. 1996; 44:80-81.

9. Bahram S, Spies T. Nucleotide sequence of a human MHC class I MICB cDNA. Immunogenetics. 1996; 43:230-233.

10. Groh V, Rhinehart R, Secrist H, Bauer S, Grabstein KH, Spies T. Broad tumor-associated expression and recognition by tumor-derived gamma delta T cells of MICA and MICB. Proc Natl Acad Sci U S A. 1999; 96:6879-6884.

11. Zhang J, Basher F, Wu JD. NKG2D Ligands in Tumor Immunity: Two Sides of a Coin. Front Immunol. 2015; 6:97.

12. Bauer S, Groh V, Wu J, Steinle A, Phillips JH, Lanier LL, Spies T. Activation of NK cells and T cells by NKG2D, a receptor for stress-inducible MICA. Science. 1999; 285:727-729.

13. Waldhauer I, Goehlsdorf D, Gieseke F, Weinschenk T, Wittenbrink M, Ludwig A, Stevanovic S, Rammensee HG, Steinle A. Tumor-associated MICA is shed by ADAM proteases. Cancer Res. 2008; 68:6368-6376.

14. Baranwal AK, Mehra NK. Major Histocompatibility Complex Class I Chain-Related A (MICA) Molecules: Relevance in Solid Organ Transplantation. Front Immunol. 2017; 8:182.

15. Groh V, Wu J, Yee C, Spies T. Tumour-derived soluble MIC ligands impair expression of NKG2D and T-cell activation. Nature. 2002; 419:734-738.

16. Zhang J, Xu Z, Zhou X, Zhang H, Yang N, Wu Y, Chen Y, Yang G, Ren T. Loss of expression of MHC class I related chain A (MICA) is a frequent event and predicts poor survival in patients with hepatocellular carcinoma. Int J Clin Exp Pathol. 2014; 7: 3123-3131.

17. Fang L, Gong J, Wang Y, Liu R, Li Z, Wang Z, Zhang Y, Zhang C, Song C, Yang A, Ting JP, Jin B, Chen L. MICA/B expression is inhibited by unfolded protein response and associated with poor prognosis in human hepatocellular carcinoma. J Exp Clin Cancer Res. 2014; 33:76.

18. Duan X, Deng L, Chen X, Lu Y, Zhang Q, Zhang $\mathrm{K}, \mathrm{Hu} \mathrm{Y}$, Zeng J, Sun W. Clinical significance of the immunostimulatory MHC class I chain-related molecule A and NKG2D receptor on NK cells in pancreatic cancer. Med Oncol. 2011; 28:466-474.

19. Chen Y, Lin WS, Zhu WF, Lin J, Zhou ZF, Huang CZ, Chen G, Shi Y, Guo ZQ, Ye YB. Tumor MICA status predicts the efficacy of immunotherapy with cytokine-induced killer cells for patients with gastric cancer. Immunol Res. 2016; 64:251-259.

20. Okita R, Yukawa T, Nojima Y, Maeda A, Saisho S, Shimizu K, Nakata M. MHC class I chain-related molecule A and B expression is upregulated by cisplatin and associated with good prognosis in patients with non-small cell lung cancer. Cancer Immunol Immunother. 2016; 65:499-509.

21. Chen Y, Lin G, Guo ZQ, Zhou ZF, He ZY, Ye YB. Effects of MICA expression on the prognosis of advanced non-small cell lung cancer and the efficacy of CIK therapy. PLoS One. 2013; 8:e69044.

22. Watson NF, Spendlove I, Madjd Z, McGilvray R, Green AR, Ellis IO, Scholefield JH, Durrant LG. Expression of the stress-related MHC class I chain-related protein MICA is an indicator of good prognosis in colorectal cancer patients. Int J Cancer. 2006; 118:1445-1452.

23. Madjd Z, Spendlove I, Moss R, Bevin S, Pinder SE, Watson NF, Ellis I, Durrant LG. Upregulation of MICA on highgrade invasive operable breast carcinoma. Cancer Immun. 2007; 7:17.

24. Holdenrieder S, Stieber P, Peterfi A, Nagel D, Steinle A, Salih HR. Soluble MICB in malignant diseases: analysis of diagnostic significance and correlation with soluble MICA. Cancer Immunol Immunother. 2006; 55:1584-1589.

25. Holdenrieder S, Stieber P, Peterfi A, Nagel D, Steinle A, Salih HR. Soluble MICA in malignant diseases. Int J Cancer. 2006; 118:684-687.

26. Chitadze G, Bhat J, Lettau M, Janssen O, Kabelitz D. Generation of soluble NKG2D ligands: proteolytic cleavage, exosome secretion and functional implications. Scand J Immunol. 2013; 78:120-129.

27. Cho H, Chung JY, Kim S, Braunschweig T, Kang TH, Kim J, Chung EJ, Hewitt SM, Kim JH. MICA/B and ULBP1 NKG2D ligands are independent predictors of good prognosis in cervical cancer. BMC Cancer. 2014; 14:957.

28. Koguchi Y, Hoen HM, Bambina SA, Rynning MD, Fuerstenberg RK, Curti BD, Urba WJ, Milburn C, Bahjat FR, Korman AJ, Bahjat KS. Serum Immunoregulatory Proteins as Predictors of Overall Survival of Metastatic Melanoma Patients Treated with Ipilimumab. Cancer Res. 2015; 75:5084-5092.

29. Li JJ, Pan K, Gu MF, Chen MS, Zhao JJ, Wang H, Liang XT, Sun JC, Xia JC. Prognostic value of soluble MICA levels in the serum of patients with advanced hepatocellular carcinoma. Chin J Cancer. 2013; 32:141-148. 
30. Wu JD, Atteridge CL, Wang X, Seya T, Plymate SR. Obstructing shedding of the immunostimulatory MHC class I chain-related gene B prevents tumor formation. Clin Cancer Res. 2009; 15:632-640.

31. Tamaki S, Sanefuzi N, Kawakami M, Aoki K, Imai Y, Yamanaka Y, Yamamoto K, Ishitani A, Hatake K, Kirita T. Association between soluble MICA levels and disease stage IV oral squamous cell carcinoma in Japanese patients. Hum Immunol. 2008; 69:88-93.

32. Tamaki S, Kawakami M, Ishitani A, Kawashima W, Kasuda S, Yamanaka Y, Shimomura H, Imai Y, Nakagawa Y, Hatake K, Kirita T. Soluble MICB serum levels correlate with disease stage and survival rate in patients with oral squamous cell carcinoma. Anticancer Res. 2010; 30:40974101 .

33. Tsukagoshi M, Wada S, Yokobori T, Altan B, Ishii N, Watanabe A, Kubo N, Saito F, Araki K, Suzuki H, Hosouchi Y, Kuwano H. Overexpression of natural killer group 2 member D ligands predicts favorable prognosis in cholangiocarcinoma. Cancer Sci. 2016; 107:116-122.

34. Zhao JZ, Mei JZ, Song W, Liu GJ, Feng RT. [Expression of major histocompatibility complex class I chain-related protein A and B in operable lung adenocarcinoma and its clinical significance]. [Article in Chinese]. Zhonghua Yi Xue Za Zhi. 2016; 96:2081-85.

35. Zhu J, Wang $\mathrm{H}, \mathrm{Xu} \mathrm{S}$, Hao Y. Clinicopathological and prognostic significance of HMGA2 overexpression in gastric cancer: a meta-analysis. Oncotarget. $2017 \mathrm{Jul} 05$. https://doi.org/10.18632/oncotarget.19001. [Epub ahead of print].

36. Dou Z, Lin S, Dai C, Lu Y, Tian T, Wang M, Liu X, Zheng Y, Xu P, Li S, Sheng Q, Deng Y, Dai Z. Pooling-analysis for diagnostic and prognostic value of MiRNA-100 in various cancers. Oncotarget. 2017; 8:62703-15. https://doi. org/10.18632/oncotarget.18697.

37. Li K, Mandai M, Hamanishi J, Matsumura N, Suzuki A, Yagi H, Yamaguchi K, Baba T, Fujii S, Konishi I. Clinical significance of the NKG2D ligands, MICA/B and ULBP2 in ovarian cancer: high expression of ULBP2 is an indicator of poor prognosis. Cancer Immunol Immunother. 2009; 58:641-652.

38. Zhang X, Yan L, Jiao W, Ren J, Xing N, Zhang Y, Zang Y, Wang J, Xu Z. The clinical and biological significance of MICA in clear cell renal cell carcinoma patients. Tumour Biol. 2016; 37:2153-2159.

39. Baginska J, Viry E, Paggetti J, Medves S, Berchem G, Moussay E, Janji B. The critical role of the tumor microenvironment in shaping natural killer cell-mediated anti-tumor immunity. Front Immunol. 2013; 4:490.

40. Collins RW, Stephens HA, Clare MA, Vaughan RW. High resolution molecular phototyping of MICA and MICB alleles using sequence specific primers. Hum Immunol. 2002; 63:783-794.

41. Stang A. Critical evaluation of the Newcastle-Ottawa scale for the assessment of the quality of nonrandomized studies in meta-analyses. Eur J Epidemiol. 2010; 25:603-605.

42. Tierney JF, Stewart LA, Ghersi D, Burdett S, Sydes MR. Practical methods for incorporating summary time-to-event data into meta-analysis. Trials. 2007; 8:16.

43. Zhou ZR, Zhang TS, Bo LI, Mao Z, Zeng XT, Liu SX. Extracting and transforming of appropriate data of Metaanalysis in survival curve. Chin J Evid Based Cardiovasc Med. 2014; 6:243-247. 